\title{
Catherine Jean Julien (1950-2011)
}

Isabelle Combès

\section{CpenEdition}

Journals

\section{Edición electrónica}

URL: https://journals.openedition.org/jsa/11994

DOI: 10.4000/jsa.11994

ISSN: 1957-7842

\section{Editor}

Société des américanistes

\section{Edición impresa}

Fecha de publicación: 20 diciembre 2011

Paginación: 397-402

ISSN: 0037-9174

\section{Referencia electrónica}

Isabelle Combès, «Catherine Jean Julien (1950-2011)», Journal de la Société des américanistes [En línea], 97-2 | 2011, Publicado el 22 enero 2012, consultado el 05 septiembre 2022. URL: http:// journals.openedition.org/jsa/11994; DOI: https://doi.org/10.4000/jsa.11994 


\section{Catherine Jean JULIEN (1950-2011)}

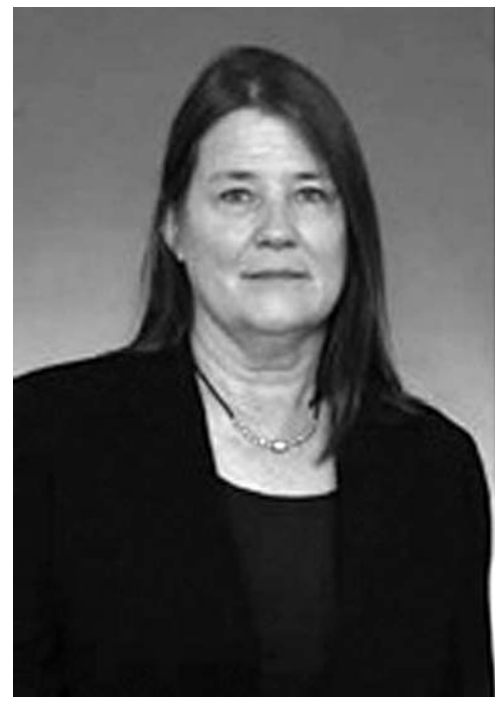

Catherine Julien ${ }^{1}$ falleció el 27 de mayo de 2011 en Turlock (California). Lo que nos queda de ella es más que el recuerdo o la tristeza: una obra extensa, llamativa, impertinente a menudo $y$, sobre todo, extremadamente bien documentada; una obra que abarcó un abanico de disciplinas (arqueología, historia, paleografía, antropología) y lugares tan distintos como el Cusco, el lago Titicaca, Tarija, Santa Cruz de la Sierra o Paraguay - con una constante: el marco temporal de sus investigaciones, todas centradas en el siglo XVI y la época inmediatamente prehispánica.

Nacida el 19 de mayo de 1950 en Stanford (California), Catherine estudió antropología en la universidad de Berkeley con John Howland Rowe, y obtuvo en 1978 su doctorado con la tesis Hatunqolla: a view of Inca rule from the Lake Titicaca Region, publicada en 1983 en Estados Unidos y traducida al español años después en Bolivia (Julien 1983; 2004b). Inició a partir de entonces una prolífica carrera de investigadora y de docente, particularmente en la universidad de Bonn (Alemania) entre 1989 y 1995 y, desde 1996 hasta su muerte, en el departamento de historia de la universidad de Western Michigan en Kalamazoo (Estados Unidos).

Formada en antropología e historia, experta en arqueología y destacada paleógrafa, Catherine logró enlazar estas diferentes disciplinas a lo largo de toda 
su obra, primero centrada en el Cusco y el altiplano peruano-boliviano y luego, a partir de 1992, en las tierras bajas de Bolivia y la región paraguaya. Publicó una decena de libros, un sinfín de artículos y capítulos de libros, y presentó un centenar de ponencias en congresos científicos a lo largo y ancho del planeta.

$\mathrm{Su}$ obra maestra seguirá siendo, sin duda, el magistral Reading Inca History publicado en 2000 y ganador de los premios Katherine-Singer-Kovacs de la Modern Languages Association y Ermine Wheeler-Voegelin de la American Society of Ethnohistory. Ella misma definía este trabajo como « una suerte de arqueología de las fuentes » (2000c, p. 12): una cabal y exacta definición de un esfuerzo que va mucho más allá de una simple crítica de fuentes. Los escritos y las crónicas quinientistas sobre la historia inca « hablan del pasado, pero revelan también muchas cosas sobre el tiempo de su composición: encapsulan dos periodos diferentes » (2000c, p. 295). Pero, para Catherine Julien, el hecho de quién escribe, para quién, por qué, con qué intereses y, en suma, el arsenal necesario para cualquier lectura crítica sólo representó un paso necesario pero no suficiente en el entendimiento de las fuentes y de la historia indígena que pretenden contar. Paso a paso, fuente por fuente, excavó las fuentes manuscritas hasta reconstituir una verdadera estratigrafía de cada una. A través de estas capas superpuestas demostró que, más allá de manipulaciones, adaptaciones e intereses, una historia inca es posible; y, más aun, que una historia inca existe y existió: una consciencia histórica que empujó a los soberanos andinos a construir y reconstruir genealogías y mitos, y que se ancló también en el presente vivido por cada uno de ello durante la paulatina extensión del imperio.

Las críticas de Julien contra la antropología estructural y sus modelos atemporales fueron duras - excesivamente duras tal vez, o muy abruptas, pero al mismo tiempo saludables para los que pretendemos hacer « etnohistoria ». Si algo me enseñó Catherine, fue eso. No sólo que las fuentes también tienen sus fuentes, su propia historia y su propia estratigrafía que debemos excavar antes de pretender entender la historia que cuentan; sino, sencillamente, que con estas fuentes hay que hacer historia. De esta manera, cuando pasó a interesarse por el corpus documental quinientista del Río de La Plata, logró re-escribir la famosa pero jamás aclarada historia de Alejo García, el portugés que llegó desde la costa atlántica hasta el piedemonte andino en los años 1530, conocido como « el primer descubridor» del imperio inca desde el Este (Julien 2005). A la manera del William Baskerville de Umberto Eco, quien sostenía que « los libros hablan de libros », Catherine Julien mostró que la saga de Alejo García se construyó a partir de azarosas hipótesis no confirmadas por las fuentes manuscritas, pero repetidas sin embargo a través de una cadena de autores que se interesaron poco en volver a los escritos originales. Parafraseando uno de sus más sugerentes títulos (2007b), Catherine logró situar a Alejo García « en su verdadero tiempo y lugar ». En la misma perspectiva, y siempre en el ámbito platense, ahondó sus críticas hacia una «etnohistoria» que privilegia los 
modelos por encima del paso del tiempo: «Quienes han sugerido que la "tierra sin mal" explica la dispersión de los guaraní-hablantes [...] adhieren a la idea de que el parentesco lingüístico es un medio para la transmisión de una cultura entre todos los hablantes y a través del tiempo»(2007b). Se acercaba así a lo que Cristina Pompa (2004) llamó el «pecado original» y otros el «mito antropológico » (Noelli 1999) de la tierra sin mal. En su cuidadoso rastreo de «los candires» (y no « el Kandire ») en las fuentes quinientistas - « en su verdadero tiempo y lugar»-, Catherine Julien no encontró elementos que sustenten, ni mucho menos justifiquen, la utilización de mitos guaraníes de Mato Grosso de finales del siglo XIX (Nimuendaju 1987) para explicar migraciones ocurridas en la época prehispánica.

Volver a las fuentes, una y otra vez, es definitivamente la principal enseñanza de Catherine Julien, y su mayor legado. Fue por eso una incansable transcriptora y editora de fuentes. Casi cada artículo suyo contiene uno o varios anexos donde da a conocer documentos en general inéditos. En este sentido, su última y ciertamente más importante publicación en el ámbito andino es la versión bilingüe de la Historia de Titu Cusi Yupanqui (2006a). En las tierras bajas, este verdadero frenesí por publicar documentos se inició en 1992, cuando se integró al proyecto Oriente Boliviano de la universidad de Bonn y se dedicó « al rastreo de archivos » (2008, p. ix). Junto con Zulema Bass-Werner y Kristina Angelis, publicó en 1997 el tomo VI de la monumental Historia de Tarija. Corpus documental, que reúne la documentación más temprana sobre esta región. Convencida que era « la única manera de arrojar luz » sobre un episodio poco conocido de la historia cruceña, a saber la rebelión de Diego de Mendoza en 1573 y la contemporánea guerra a los chiriguanaes, publicó en 2003 una serie de cinco documentos muy poco conocidos sobre este periodo. Pero su obra mayor en este sentido es sin duda su Desde el Oriente. Documentos para la historia del Oriente boliviano y Santa Cruz la vieja (1542-1597), que en 2008 reunió 25 largos documentos sobre la historia temprana de la ciudad de los llanos y sus lazos con Asunción del Paraguay. La muerte no le permitió concluir la publicación de los Comentarios de Álvar Núñez Cabeza de Vaca y la documentación relacionada con sus exploraciones del río Paraguay y el Pantanal: el proyecto queda hoy en manos del lingüista Pablo Pastrana-Pérez, con quien lo dirigía.

No se trata del único proyecto dejado en suspenso, y me acuerdo de las locas charlas cuando queríamos adentrarnos en el Pantanal en busca de los antiguos xarayes, o volver a emprender la ruta que siguió Domingo de Irala en 1542. La « Señora siglo XVI » se fue pero su obra perdura, y con ella la pasión que tan bien sabía transmitir. Seguir adelante a su manera, fuente tras fuente, es sin duda el mejor homenaje que su memoria merece. 


\section{Nota}

1. La fotografía de Catherine Julien es extraída de la página web de la Western Michigan University.

\section{REFERENCIAS CITADAS}

NimuendaJu Curt Unkel

1987 As lendas da criação e destruição do mundo como fundamentos da Religião dos Apapocúva-Guaraní, HUCITEC/Universidade de São Paulo, São Paulo [1914].

NoElli Francisco

1999 «Curt Nimuendaju e Alfred Métraux: a invenção da busca da "terra sem mal”" ", Suplemento Antropológico, 34 (2), pp. 123-166, Asunción.

Pompa Cristina

2004 "O profetismo tupi-guarani: a construção de um objeto antropológico », Revista de Indias, 44 (230), pp. 141-174, Madrid.

\section{Principales PUblicACiONES DE CATHERINE JULIEN}

1981 «A late burial from Cerro Azoguini, Puno», Ñawpa Pacha, 19, pp. 129-154, Berkeley.

1982 "Inca decimal administration in the Lake Titicaca region », in George Collier, Renato Rosaldo y John Wirth (eds), The Inca and Aztecs States, 1400-1800, Academic Press, New York, pp. 119-151.

1983 Hatunqolla: a view of Inca rule from the Lake Titicaca region, University of California Press, Berkeley.

1985 «Guano and resource control in sixteenth-century Arequipa », in Shozo Masuda, Izumi Shimada y Craig Morris (eds), Andean ecology and civilization: an interdisciplinary perspective on Andean ecological complementary, University of Tokyo Press, Tokyo, pp. 185-231.

1987 "The Uru tribute category. Ethnic boundaries and empire in the Andes », Proceedings of the American Philosophical Society, 131 (1), pp. 53-92, Philadelphia.

1988 «How Inca decimal administration worked», Ethnohistory, 35 (1), pp. 257-279.

1991 Condesuyo: the political division of territory under Inca and Spanish rule, Bonn University, col. « Bonner Amerikanistisch Studien » 19, Bonn.

1993 "Finding a fit: archaeology and ethnohistory of the Incas ", in Mickael Malpass (ed.), Provincial Inca: archaeological and ethnohistorical assessment of the impacts of the Inca state, University of Iowa Press, Iowa City, pp. 177-223. 
1995 «El Tawantinsuyu », in Luis Guillermo Lumbreras (ed.), Historia de América Latina. 1. Las sociedades aborígenes, Universidad Andina Simón Bolívar, Quito, pp. 439-497.

1997a «Colonial perspectives on the Chiriguaná (1528-1574) », in María Susana Cipolletti (ed.), Resistencia y adaptación nativas en las tierras bajas latinoamericanas, Abya-Yala, col. «biblioteca Abya-Yala»35, Quito, pp. 17-76.

1997b Historia de Tarija. Corpus documental. Tomo VI, ed. de Catherine Julien, Kristina Angelis y Zulema Bass-Werner, Universidad autónoma «Juan Misael Saracho », Tarija.

1998a «La encomienda del Inca», Actas del IV Congreso Internacional de Etnohistoria, 2, pp. 489-516, Pontificia Universidad Católica del Perú, Lima.

1998b «La organización parroquial del Cuzco », Tawantinsuyu, 5, pp. 82-96.

1998c «Coca production on the Inca frontier: the yungas of Chuquioma », Andean Past, 5, pp. 129-160.

1998d Die Inka. Geschichte, kultur, religion, C. H. Beck, Munich.

1998e Toledo y los Lupacas: las Tasas de 1574 y 1579, ed. de Catherine Julien, Kristina Angelis, Alexander Voß y Annette Hauschild, Bonn University, col. « Bonner Amerikanistisch Studien » 23, Bonn.

1999a «History and art in translation: the paños and other objects collected by Francisco de Toledo ", Colonial Latin American Review, 8 (1), pp. 61-89.

1999b «Spanish Use of Inca Textile Standards », Indiana, 16, pp. 57-81.

2000a «Francisca Pizarro, la cuzqueña, y su madre, la coya Ynguill », Revista del Archivo Regional del Cusco, 15, pp. 53-74.

2000 b «Inca estates and the encomienda: Hernando Pizarro's holdings in Cusco », Andean Past, 6, pp. 229-275.

2000c Reading Inca history, University of Iowa Press, Iowa City.

2002a "Punchao en España », in Javier Flores Espinoza y Rafael Varón Gabai (eds), El hombre y los Andes. Homenaje a Franklin Pease G. Y., tomo 2, Pontificia Universidad Católica del Perú, Lima, pp. 709-715.

2002b «Las Huacas Pacariscas de Arequipa y el volcán Misti », Historia. Revista de la escuela profesional de Historia, 5, pp. 9-40, Arequipa.

2002c «Diego Maldonado y los chancas », Revista Andina, 34, pp. 183-197.

2002d «Identidad y filiación por suyu en el imperio incaico», Boletín de arqueología de la Pontificia Universidad Católica del Perú, 6, pp. 11-22.

2003a «Amazonas en el Pantanal: el entorno histórico de un mito», in Actas del primer congreso sudamericano de historia [cd-rom], Universidad de Santa Cruz/Instituto panamericano de geografía e historia/Cotas, Santa Cruz.

2003b «Rebeldía en Santa Cruz de la Sierra en tiempos del virrey Francisco de Toledo ", Revista de Humanidades y Ciencias Sociales, 9 (1-2), pp. 1-42, Universidad Autónoma Gabriel René Moreno, Santa Cruz.

2004a «Las tumbas de Sacsahuaman y el estilo Cuzco-Inca», Nawpa Pacha, 25-27 (1987-89), pp. 1-125, Berkeley.

2004b Hatunqolla. Una perspectiva sobre el imperio incaico desde la región del lago Titicaca, maestría en historias andinas y amazónicas, Universidad Mayor de 
San Andrés/Colegio Nacional de Historiadores de Bolivia/Producciones CIMA, La Paz.

2005 «Alejo García en la historia », Anuario de estudios bolivianos, archivísticos y bibliográficos, 11, pp. 223-266, Sucre.

2006a History of how the Spaniards arrived in Peru (Titu Cusi Yupanqui), edición bilingüe, introducción y notas de Catherine Julien, Hackett Publishing Company, Indianapolis.

2006b " La descripción de la población del oriente boliviano en el siglo XVI », in Isabelle Combès (ed.), Definiciones étnicas, organización social y estrategias políticas en el Chaco y la Chiquitania, IFEA/SNV/El País, Santa Cruz, pp. 49-67.

2007a Cuzco: del mito a la historia (con Jorge Flores Ochoa et al.), Banco de Crédito del Perú, Cuzco.

2007b «Kandire in real time and space: sixteenth-century expeditions from the Pantanal to the Andes ", Ethnohistory, 54 (2), pp. 245-272.

2008 Desde el Oriente. Documentos para la historia del Oriente boliviano y Santa Cruz la vieja (1542-1597), Fondo editorial municipal, Santa Cruz.

s. d. «Andes y Amazonas: la historia de una diferencia », ponencia presentada en St Andrews (Escocia), septiembre de 2005 [en prensa].

Isabelle CombÈs IFEA UMIFRE $n^{\circ} 17$, CNRS/MAE, Santa Cruz de la Sierra, Bolivia 